\title{
Computer Aided Drug Design: A Novel Loom To Drug Discovery
}

\author{
Syed Sarim Imam and Sadaf Jamal Gilani* \\ Department of Pharmaceutics, Glocal School of Pharmacy, The Glocal University, Saharanpur, U.P, India \\ Department of Pharmaceutical Chemistry, Glocal School of Pharmacy, The Glocal University, Saharanpur, U.P, India
}

Submission: February 15, 2017; Published: February 20, 2017

*Corresponding author: Dr. Sadaf Jamal Gilani, Associate Professor, Department of Pharmaceutical Chemistry, Glocal School of Pharmacy, The Glocal University, Saharanpur-247121, Uttar Pradesh, India, Tel: 09997939221; Email: gilanisadaf@gmail.com, sarimimam@gmail.com

\begin{abstract}
Computer-Aided Drug Design (CADD) is a growing effort to apply computational power to the combined chemical and biological space in order to streamline drug discovery design, development, and optimization. This technique of drug discovery and development are very time and resources consuming processes. But this tool can act as a virtual shortcut, assisting in the expedition of this long process and potentially reducing the cost of research and development. This application has been widely used in the biomedical arena, in silico design is being utilized to expedite and facilitate hit identification, hit-to-lead selection, optimize the pharmacokinetic profile, toxicity profile and avoid safety issues. Here in this mini review, we present overviews of computational methods used in the different arena of drug discovery and focusing some of the recent successes.
\end{abstract}

Keywords: Computer-aided drug design (CADD); In-silico design; Computational methods

\section{Introduction}

Initially, the design of new drugs was based on the prototypical molecule, usually a natural product and making structural modifications. For designing of new drugs the understanding of the etiology of the disease and the structure of the receptor where the ligand (drug) will bind is very much important. Now a day, there is increasing computational power coupled with applicable software, has led to more focused approaches to the development of new drugs [1]. The launch of a new drug to market is a long-term process that costs billions of dollars and the probability of a failure in the drug discovery is high. About $90 \%$ of the new drugs entering clinical trials fail to get FDA approval and reach the consumer market [2]. Therefore, computeraided drug discovery (CADD) is a novel tool for drug discovery getting a lot of attention in the pharmaceutical industry. It has immense potential and promise in the drug discovery workflow. This tool not only reduces the costs associated with new drug discovery by ensuring that best possible lead compound for the animal studies. It may also reduce the time to reach the drug to market [3]. It is helpful to identify lead drug compounds, can predict pharmacological actions, possible side effects, and help in improving the bioavailability drug [4]. CADD have the three major roles in drug discovery campaign:

a. It can reduce a large number of compounds into smaller sets of active compounds that can be experimentally tested. b. Optimization of lead compounds, to check absorption, distribution, metabolism, excretion, and the potential for toxicity (ADMET);

C. Design novel compounds, by piecing together fragments into novel chemo types [5].

In this mini-review, we will discuss the importance of structure-based and ligand-based methods used in CADD (Figure $1 \&$ Table 1), and target on recent successes of CADD in the pharmaceutical industry.

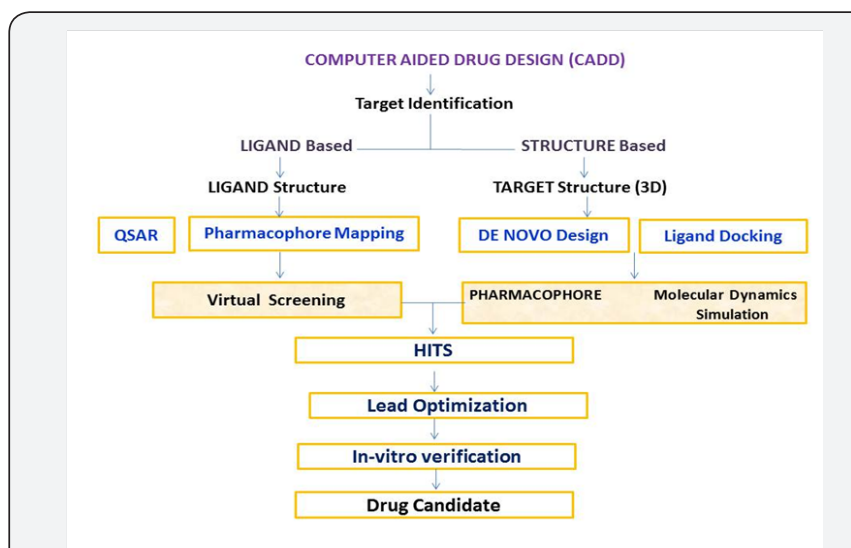

Figure 1: Schematic representation of CADD in drug discovery. 
Organic and Medicinal Chemistry International Journal

Table 1:Database used to provide different chemical compounds using Drug Design technique

\begin{tabular}{|c|c|c|c|}
\hline S. No & Database & Type & References \\
\hline 1 & LIGAND & $\begin{array}{l}\text { Chemical compounds with target and } \\
\text { reactions information. }\end{array}$ & [35] \\
\hline 2 & Zinc & $\begin{array}{l}\text { Commercially available annotated } \\
\text { compounds. }\end{array}$ & [36] \\
\hline 3 & Drug Bank & $\begin{array}{l}\text { Detailed drug information with complete } \\
\text { drug target data. }\end{array}$ & [37] \\
\hline 4 & Chem DB & $\begin{array}{l}\text { Commercially available annotated } \\
\text { compounds. }\end{array}$ & {$[38,39]$} \\
\hline 5 & Pub Chem & Bio-activities of small molecules. & [40] \\
\hline 6 & PD Be Chem & $\begin{array}{l}\text { Ligands and small molecules referred in } \\
\text { PDB }\end{array}$ & [41] \\
\hline 7 & $\begin{array}{c}\text { WOMBAT Data base } \\
\text { (World of Molecular Bio Ac Trinity) }\end{array}$ & $\begin{array}{l}\text { Bioactivity data for compounds reported } \\
\text { in literatures. }\end{array}$ & {$[42,43]$} \\
\hline 8 & $\begin{array}{c}\text { MDDR } \\
\text { (MDL Drug Data Report) }\end{array}$ & Drugs under development or released. & [43] \\
\hline 9 & 3D MIND & $\begin{array}{l}\text { Molecules with target interaction and } \\
\text { tumor cell line screen data. }\end{array}$ & [44] \\
\hline 10 & Accelrys Available Chemicals Directory (ACD) & $\begin{array}{l}\text { Consolidated list from chemical } \\
\text { suppliers. }\end{array}$ & [45] \\
\hline
\end{tabular}

\section{Discussion}

CADD tools can be classified into two types:

\section{A.Ligand-based CADD}

The ligand-based CADD tools, exploits the knowledge of known active and inactive molecules through chemical similarity searches and quantitative structure-activity relation (QSAR) models [5].

\section{B.Structure-based CADD}

The structure-based CADD depend on the knowledge of the target protein structure to calculate interaction energies for all tested compounds [6].

\section{Structure-based drug discovery (SBDD)}

Structure-based computer-aided drug design (SBCADD) relies on the ability to determine and analyze $3 \mathrm{D}$ structures of biologic molecules. The core hypothesis of this approach is that a molecule's ability to interact with a specific protein and shows a desired biologic effect depends on its ability to favorably interact with a particular binding site on that protein [4]. The two commonly used methods in SBDD are molecular docking approaches and de novo ligand design. Molecular dynamics (MD) simulations are frequently used in SBDD to give insights into the binding of ligands with target proteins, the pathways of interaction and to account for target flexibility $[7,8]$. Saquinavir is one of the first HIV-1 protease targeted drugs to reach the market [9] that was developed by using SBDD tool.

\section{Target Structure Information}

In order to use SBDD tools, information about target structures needs to be known. Target information is usually obtained experimentally by nuclear magnetic resonance or $\mathrm{X}$-ray crystallography techniques. When these above techniques not available then, computational methods such as homology modeling may be used to predict the three- dimensional structure of targets. By knowing the structure of lead compound makes easy to use structure-based tools such as virtual high throughput screening and direct docking methods on targets [10].

\section{Homology Modeling}

Homology modeling is a specific type of comparative modeling in which the template and target proteins share the same evolutionary origin. This comparative modeling technique involves the following stages:

i. To serve as a template for structure identification of related proteins

ii. Replica of coordinates for confidently aligned regions,

iii. Arrangement of alignment of both target and template proteins,

iv. Builds missing atom coordinates of the target structure,

v. Evaluation and model refinement. e.g., PSIPRED and MODELER [11,12]. 


\section{De novo Design}

De novo structure-based design can be accomplished by either a ligand linking or ligand-growing approach. In the ligandgrowing approach, a fragment is docked into the binding site and the ligand is extended by adding functional groups to the fragment [13].

\section{Molecular docking}

Docking applications need to rapidly and accurately assess protein-ligand complexes, i.e., approximate the energy of the interaction. A ligand docking experiment may produce a number of target-ligand complex conformations, and an efficient scoring function is necessary to rank these complexes. The selection of different valid binding mode predictions from invalid predictions is done. There are four different types of scoring functions:

i. Force-field or molecular mechanics-based scoring functions [14],

ii. Empirical scoring functions [15],

iii. knowledge-based scoring functions[16],

iv. Consensus scoring functions [17].

\section{Structure-based screening(VHTS) \\ virtual \\ high-throughput}

SB-vHTS selects for ligands predicted to bind a particular binding site as opposed to traditional HTS that experimentally asserts general ability of a ligand to bind, inhibit, or allosterically alter the protein's function. The key steps are as follows:

i. Preparation of the target protein

ii. Develop library for docking,

iii. Determination of favorable binding position for each compound,

iv. Position of the docked structures $[18,19]$.

Atomic-Detail Docking: The goal of SB-vHTS is to identify most probable hits that can bind to a target structure. The main objective of this atomic-detail refinement of initial docking is:

i. Improved judgment if ligand will actually engage the target,

ii. Accurate prediction of complex conformation,

iii. Accurate prediction of binding affinity [4].

\section{Pharmacophore Model}

The pharmacophore model has been used extensively in drug discovery for virtual screening, de novo design, and lead optimization [20]. In this model, the target binding site summarizes steric and electronic features needed for the optimal interaction of a ligand with a target. Most common properties that are used to define pharmacophore sare hydrogen bond acceptors, hydrogen bond donors, basic groups, acidic groups, partial charge, aliphatic hydrophobic moieties, and aromatic hydrophobic moieties.

\section{Molecular Dynamics Simulations}

Molecular dynamics (MD) simulation is one of the tools that is extensively and routinely used to understand protein motions and conformational space that is accessible for protein structures. The most widely used molecular dynamics software packages used are NAMD [21], GROMACS [22] and AMBER [23]. The typical time-scale of a molecular dynamics simulation is in the order of nanoseconds to microseconds. Millisecond-scale MD simulations are possible with high-speed supercomputers, although most computational scientists do not have access to such powerful machines [24]. This is considered a major limitation of MD. Enhanced sampling methods have been introduced to address this issue [25]. Several methods of enhanced sampling are introduced in literature, including: accelerated molecular dynamics [26], met dynamics [26], umbrella sampling [27] and temperature-accelerated molecular dynamics [28].

\section{Ligand-based drug design (LBDD)}

Ligand-based drug design is considered an indirect approach to drug discovery in that it does not necessitate knowledge of the structure of the target of interest. Pharmacophoremodeling, molecular similarity approaches, and QSAR (quantitative structure-activity relationship) modeling's are some popular LBDD approaches [5].

\section{Quantitative structure-Activity Relationship}

Quantitative structure-activity relationship (QSAR) model give the mathematical relation between structural attributes and target response of a set of chemicals [29,30]. Hansch-Fujita approach (Classic QSAR model) involves the correlation of various electronic, hydrophobic, and steric features with biologic activity. The general workflow of a QSAR-based drug discovery project is to first collect a group of active and inactive ligands then develop a set of mathematical descriptors that describe the physicochemical and structural properties of those compounds. The basic steps involved in the QSAR method can be summarized as follows [10]:

a. The active molecules that bind to the desired drug target and their activities are identified through a database search.

b. Identification of physicochemical molecular features (fingerprint) affecting biological activity (e.g. bond, atom, functional group counts, surface area etc.).

c. Building of a QSAR between the biological activity and features of the drug molecules.

d. Validation of the QSAR biological activity predictive power.

e. Use of the QSAR model to optimize the known active compounds to maximize the biological activity. 


\section{Organic and Medicinal Chemistry International Journal}

f. The new optimized drug molecule activities are tested experimentally.

\section{Pharmacophore Mapping/ Modeling}

A pharmacophore is a molecular framework that defines the essential features responsible for the biological activity of a compound. When structural information about the drug target is limited, then pharmacophore models may be built using the structural characteristics of active ligands that bind to the target [30]. Pharmacophore model construction steps can be summarized as follows [10].

a. The active compounds known to be binding to the desired target are identified either by a literature search or a database search.

b. (a) For a 2D pharmacophore model essential atom type and their connectivity is defined

(b) For a 3D Pharmacophoremodeling the conformations are defined using IUPAC nomenclature.

c. Ligand alignment is used to find common features required in binders.

d. Pharmacophore model building.

e. Ranking of the pharmacophore models and selecting the best models.

f. Validation of pharmacophore models.

\section{Lead optimization and assessment of ADME and drug} safety

In the last few decades, Computational ADME methods have shown interest in pharmaceutical companies [31]. During lead optimization, the effectiveness of drug molecule is generally enhanced by observing the desired pharmacological profiles to reach the required affinity, pharmacokinetic properties, drug safety, and ADME (absorption, distribution, metabolism, and excretion/elimination) properties. By increasing the affinity of a drug molecule to the target site its bio-efficacy can be enhanced. QikProp is an ADME program offered by Schrodinger that predicts pharmaceutically relevant and physically significant descriptors for small drug-like molecules [32]. Another package Vol Surf can be used to generate ADME models and calculate ADME profile [33]. These ADME models can then be used to predict the behavior of novel molecules. Thus filters for ADME properties are important for drug screening [34].

\section{Drug Candidate}

Absorption, distribution, metabolism and elimination/ excretion properties, commonly abbreviated ADME, as well as toxicity, are important for the ultimate success or failure of a possible drug candidate. Adverse effects in animal models or even clinical trials can be reduced by filtering drug candidates by their ADME properties in early stages.

\section{Conclusion}

The extensive variety of computational tools used in drug discovery campaigns suggests that there are no fundamentally superior techniques. The performance of methods varies greatly with the target protein, available data, and available resources. CADD has had a significant impact on the discovery of various therapeutics that are currently helping treat patients. Despite the successes, it also faces challenges such as accurate identification and prediction of ligand binding modes and affinities. The phenomenon of drug polymorphism is one of the challenging areas in drug discovery, and it occurs when a drug has different forms which differ structurally and found chemically identical. This can have a great impaction the success of a drug. The field of CADD is continuously evolving with improvements being made in each and every area. With the current successes, there is a promising future for computational methods to aid in the discovery of many more therapeutics in the future.

\section{Acknowledgement}

Authors are thankful to the library (Glocal School of Pharmacy) for providing literature facility.

\section{References}

1. Wilson, Gisvold's (2011) textbook of organic medicinal and pharmaceutical chemistry. - 12th ed. / edited by John M, Beale Jr, John H. Block 17-25

2. Tollman P (2001) A Revolution in R\&D: How genomics and genetics are transforming the biopharmaceutical industry. The Boston Consulting Group 4-64.

3. Yang L, Wang W, Sun, Q Xu F, Niu Y, et al. (2016) Development of novel proteasome inhibitors based on phthalazinone scaffold. Bioorg Med Chem Lett 26(12): 2801-2805.

4. Gregory Sliwoski, Sandeepkumar Kothiwale, Jens Meiler, Edward W Lowe Jr (2013) Computational Methods in Drug Discovery. Pharmacol Rev 66: 334-395.

5. Acharya C, Coop A, Polli J E, MacKerell A D (2011) Recent advances in ligand-based drug design: relevance and utility of the conformationally sampled pharmacophore approach. Curr Comput Aided Drug Des 7(1): 10-22.

6. Kalyaanamoorthy S, Chen Y P (2011) Structure-based drug design to augment hit discovery. Drug Discov Today 16(17-18): 831-839.

7. Wang Y, Shaikh S A, Tajkhorshid E (2010) Exploring transmembrane diffusion pathways with molecular dynamics. Physiology 25(3): 142154.

8. Hanson S M, Newstead S, Swartz K J, Sansom M S (2015) Capsaicin interaction with TRPV1 channels in a lipid bilayer: molecular dynamics simulation. Biophys J 108(6): 1425-1434.

9. Craig JC, Duncan I B, Hockley D, GriefC, Roberts N A, et al.(1991) Antiviral properties of Ro 31-8959, an inhibitor of human immunodeficiency virus (HIV) proteinase. Antiviral Res 16(4): 295-305.

10. Sumudu P, Leelananda, Steffen Lindert (2016) Computational methods in drug discovery, Beilstein J Org Chem 12: 2694-2718.

11. Buchan DW, Ward SM, Lobley AE, Nugent TC, Bryson K, et al. (2010) Protein annotation and modelling servers at University College London. Nucleic Acids Res 38: W563-W568. 


\section{Organic and Medicinal Chemistry International Journal}

12. Martí Renom MA, Stuart AC, Fiser A, Sánchez R, Melo F, et al. (2000) Comparative protein structure modeling of genes and genomes. Annu Rev Biophys Biomol Struct 29: 291-325.

13. Shuker SB, Hajduk PJ, Meadows RP, Fesik SW (1996) Discovering highaffinity ligands for proteins: SAR by NMR. Science 274: 1531-1534

14. Fischer B, Fukuzawa K, Wenzel W (2008) Receptor-specific scoring functions derived from quantum chemical models improve affinity estimates for in-silico drug discovery. Proteins 70(4): 1264-1273.

15. Artemenko N J (2008) Distance dependent scoring function for describing protein-ligand intermolecular interactions. Chem Inf Model 48(3): 569-574

16. Huang SY, Zou X (2006) An iterative knowledge-based scoring function to predict protein-ligand interactions: I. Derivation of interaction potentials. J Comput Chem 27(15): 1866-1875.

17. Oda A, Tsuchida K, Takakura T, Yamaotsu N, Hirono S (2006) Comparison of consensus scoring strategies for evaluating computational models of protein-ligand complexes. J Chem Inf Model 46(1): 380-391.

18. Becker OM, Dhanoa DS, Marantz Y, Chen D, Shacham S, et al. (2006) An integrated in silico 3Dmodel-driven discovery of a novel, potent, and selective amid sulfonamide 5-HT1A agonist (PRX-00023) for the treatment of anxiety and depression. J Med Chem 49(11): 3116-3135.

19. Lu IL, Huang CF, Peng YH, Lin YT, Hsieh HP, et al. (2006) Structurebased drug design of a novel family of PPARgamma partial agonists: virtual screening, X-ray crystallography, and in vitro/in vivo biological activities. J Med Chem 49(9): 2703-2712

20. Yang SY (2010) Pharmacophore modeling and applications in drug discovery: challenges and recent advances. Drug Discov Today 15(1112): 444-450.

21. Phillips J C, Braun R, Wang W, Gumbart J, Tajkhorshid E, et al. (2005) Scalable molecular dynamics with NAMD. Comput Chem 26: 17811802.

22. Scott W R P, Hunenberger P H, Tironi I G, Mark A E, Billeter S R, et al. (1999) The GROMOS Biomolecular Simulation Program Package. Phys Chem A 103(19): 3596-3607.

23. Weiner P K, Kollman P A J (1981) AMBER: Assisted model building with energy refinement. A general program for modeling molecules and their interactions. Comput Chem 2(3): 287-303.

24. Shaw D E, Dror R O, Salmon J K, Grossman J P, Mackenzie K M, et al. (2009) Millisecond-scale molecular dynamics simulations on Anton. In Proceedings of the 2009 ACM/IEEE Conference on Supercomputing (SC09), Washington, DC. ACM Press pp 1-11.

25. Feixas F, Lindert S, Sinko W, McCammon J A (2014) Exploring the role of receptor flexibility in structure-based drug discovery. Biophys Chem 186: 31-45.

26. Wang Y, Harrison C B, Schulten K, McCammon J A (2011) Implementation of Accelerated Molecular Dynamics in NAMD. Comput Sci Discovery 4(1): 015002

27. Kastner J (2011) Umbrella sampling, Wiley Interdiscip. Rev Comput Mol Sci 1(2): 932-942.

28. Selwa E, Huynh T, Ciccotti G, Maragliano L, Malliavin T E (2014) Temperature-accelerated molecular dynamics gives insights into globular conformations sampled in the free state of the AC catalytic domain. Proteins Struct Funct Bioinf 82(10): 2483-2496.

29. Zhang S (2011) Computer-aided drug discovery and development. Methods Mol Biol 716: 23-38.

30. Lin S K (2000) Pharmacophore Perception, Development and Use in Drug Design. Edited by Osman F. Güner. Molecules 5: 987-989.

31. Ekins S, Waller C L, Swaan P W, Cruciani G, Wrighton S A, et al. (2000) Progress in predicting human ADME parameters in silico. J Pharmacol Toxicol Methods 44(1): 251-272.

32. Laoui A, Polyakov V R (2011) Web services as applications' integration tool: QikProp case study. J Comput Chem 32(9): 1944-1951.

33. Cruciani G, Pastor M, Guba W (2000) Vol Surf: a new tool for the pharmacokinetic optimization of lead compounds. Eur J Pharm Sci 11 (Suppl. 2): S29-S39.

34. van de Waterbeemd H, Gifford E (2003) ADMET in silico modelling towards prediction paradise? Nat Rev Drug Discovery 2(3): 192-204.

35. Goto S, Okuno Y, Hattori M, Nishioka T, Kanehisa M (2002) LIGAND: database of chemical compounds and reactions in biological pathways. Nucleic Acids Res 30: 402-404.

36. Irwin JJ, Shoichet BK (2005) ZINC-a free database of commercially available compounds for virtual screening. J Chem Inf Model 45: 177182.

37. Wishart DS, Knox C, Guo AC, Shrivastava S, Hassanali M, et al. (2006) DrugBank: a comprehensive resource for in silico drug discovery and exploration. Nucleic Acids Res 34 (Database issue): D668-D672.

38. Chen J, Swamidass SJ, Dou Y, Bruand J, Baldi P, (2005) Chem DB: a public database of small molecules and related chemoinformatics resources. Bioinformatics 21(22): 4133-4139.

39. Chen JH, Linstead E, Swamidass SJ, Wang D, Baldi P (2007) ChemDB update- full-text search and virtual chemical space. Bioinformatics 23 : 2348-2351

40. Wheeler DL, Barrett T, Benson DA, Bryant SH, Canese $\mathrm{K}$, et al (2006) Database resources of the National Center for Biotechnology Information. Nucleic Acids Res 35 (Database issue): D5-D12.

41. Dimitropoulos D, Ionides J, Henrick K (2006) Using PDBeChem to Search the PDB Ligand Dictionary, in Current Protocols in Bioinformatics. John Wiley \& Sons 14.13.11-14.13.13.

42. Ekins S, Mestres J, Testa B (2007) In silico pharmacology for drug discovery: methods for virtual ligand screening and profiling. $\mathrm{Br}$ Pharmacol 152(1): 9-20.

43. Hristozov DP, Oprea TI, Gasteiger J (2007) Virtual screening applications: a study of ligand-based methods and different structure representations in four different scenarios. J Comput Aided Mol Des 21(10): 617-640.

44. Mandal S, Moudgil M, Mandal SK (2009) Rational drug design. Eur J Pharmacol 625: 90-100.

45. Accelrys (2013) Accelrys metabolite. Available from http://accelrys. com/products/databases/bioactivity/metabolite.html. 


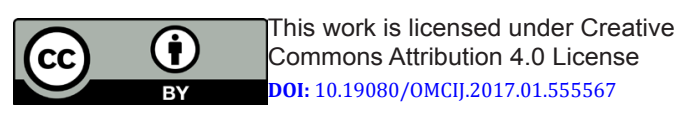

\begin{tabular}{|l|}
\multicolumn{1}{|c|}{ Your next submission with Juniper Publishers } \\
will reach you the below assets \\
- Quality Editorial service \\
- Swift Peer Review \\
- Reprints availability \\
- E-prints Service \\
- Manuscript Podcast for convenient understanding \\
- Global attainment for your research \\
- Manuscript accessibility in different formats \\
( Pdf, E-pub, Full Text, Audio) \\
- Unceasing customer service \\
Track the below URL for one-step submission \\
https://juniperpublishers.com/online-submission.php \\
\hline
\end{tabular}

